\title{
Potential Factors Affecting the Anticoagulation Control in Patients Treated with Warfarin: Results WARFARIN-TR Study
}

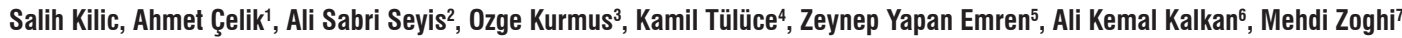 \\ Department of Cardiology, Doctor Ersin Arslan Research and Training Hospital, Gaziantep, 'Department of Cardiology, Faculty of Medicine, Mersin University, \\ Mersin, ${ }^{2}$ Department of Cardiology, Istinye University Liv Hospital, Istanbul, ${ }^{3}$ Department of Cardiology, Ufuk University, Faculty of Medicine, Ankara, \\ ${ }^{4}$ Department of Cardiology, Karsiyaka State Hospital, ${ }^{6}$ Department of Cardiology, Tepecik Research and Training Hospital, ${ }^{7}$ Department of Cardiology, Faculty of \\ Medicine, Ege University, Izmir, ${ }^{5}$ Department of Cardiology, Sandikli State Hospital, Afyon, Turkey
}

\section{Abstract}

Background: In the present study, we aimed to evaluate the factors that might be caused by adequate anticoagulation control in patients treated with warfarin for any reason. Methods: The WARFARIN-TR (The Awareness, Efficacy, Safety, and Time in Therapeutic Range of Warfarin in Turkish Population) study included 4987 patients using warfarin between January 1, 2014 and December 31, 2014. Time in therapeutic range (TTR) was calculated according to F. R. Roosendaal's algorithm with linear interpolation. The study population divided into two groups; adequate international normalized ratio (INR) control when TTR $\geq 70 \%$ (Group $1, n=1068,21.4 \%$ ) and inadequate INR control when TTR $<70 \%$ (Group 2, $n=3919,78.6 \%$ ). All demographic and clinic characteristics of the patients were compared to determine possible factors that might be cause adequate warfarin use. Results: The mean age of the study population was $60.7 \pm 13.5$ years, and there was no significant difference between groups. The mean TTR value of Group 1 was significantly higher than Group $2(80 \pm 8.5$ vs. $40.9 \pm 17.2 ; P<0.001)$. The traditional cardiovascular risk factors were similar between groups except hypertension (Group $151.4 \%$ and Group 2 56.4\%; $P=0.004$ ) and chronic kidney disease (Group $18.3 \%$ and Group $25.5 \% ; P=0.001$ ). There were no significant differences between groups regarding bleeding. The awareness of warfarin use was significantly higher in Group 1 patients than Group 2 patients. Multivariate logistic regression analysis revealed that age (odds ratio $[\mathrm{OR}], 1.007 ; P=0.014)$, hypertension $(\mathrm{OR}, 0.821 ; P=0.01$ ), atrial fibrillation $(\mathrm{OR}, 1.180 ; P=0.033$ ), chronic kidney disease (OR, 1.697; $P<0.001)$, to know warfarin use reason $(\mathrm{OR}, 1.699 ; P<0.001)$, and know to food-drug interaction with warfarin $(\mathrm{OR}, 1.583 ; P<0.001)$ were independent predictors of adequate coagulation. Conclusion: Our study demonstrated that a low proportion of patients taking warfarin achieve an adequate TTR in daily practice. Furthermore, the patients with adequate TTR are more aware of warfarin use.

Keywords: Adequate anticoagulation, warfarin, warfarin awareness

\section{INTRODUCTION}

Warfarin is an effective oral anticoagulant which is used for the prevention of thromboembolic events especially in patients with atrial fibrillation (AF) and prosthetic valve. Warfarin reduces the stroke by $64 \%$ compared to the placebo in patients with $\mathrm{AF}$, and it is the unique treatment for prosthetic valve patients. ${ }^{[1,2]}$ The efficacy and safety of warfarin are dependent on maintenance of the international normalized ratio (INR). The target INR values alter according to the reason of warfarin use; the TTR should be above $70 \%$ for optimal efficacy and safety of warfarin use. ${ }^{[3-6]}$ The risk of total mortality and major bleeding increases with TTR value below $70 \%{ }^{[3,5]}$ However, many studies from Turkey

\begin{tabular}{|l|l|}
\hline \multicolumn{2}{|c|}{ Access this article online } \\
\hline Quick Response Code: & Website: \\
\hline & http:/www.ijcva.com \\
\cline { 2 - 2 } & \\
\hline
\end{tabular}

have shown that the number of patients with TTR value above $70 \%$ is very low in daily practice. Previous studies have shown that many factors may cause a low rate of TTR in different study populations.

In the present study, we aimed to evaluate the factors that might be caused by adequate anticoagulation control in patients treated with warfarin in the WARFARIN-TR (The Awareness,

Address for correspondence: Dr. Salih Kilic Department of Cardiology, Doctor Ersin Arslan Research and Training Hospital, Sahinbey, Gaziantep, Turkey. E-mail: kilicsalihhh@gmail.com

This is an open access journal, and articles are distributed under the terms of the Creative Commons Attribution-NonCommercial-ShareAlike 4.0 License, which allows others to remix, tweak, and build upon the work non-commercially, as long as appropriate credit is given and the new creations are licensed under the identical terms.

For reprints contact: reprints@medknow.com

How to cite this article: Kilic S, Çelik A, Seyis AS, Kurmus O, Tülüce K, Emren ZY, et al. Potential factors affecting the anticoagulation control in patients treated with warfarin: Results WARFARIN-TR study. Int J Cardiovasc Acad 2018;4:86-9. 
Efficacy, Safety, and Time in Therapeutic Range of Warfarin in Turkish Population) population study.

\section{Methods}

The design, conduct, and both main and subgroup results of the WARFARIN-TR study have been presented previously. ${ }^{[7-9]}$ In brief, WARFARIN-TR study is a multi-center prospective observational study included 42 centers from 24 cities in seven regions of Turkey. Patients $(n=4987$, mean age: $60.7 \pm 13.5$ years, $44.9 \%$ male) attended follow-ups for 12 months. Of the total number of patients, 2124 (42.6\%) had a mechanical valve, 1918 (38.4\%) had nonvalvular AF, and 985 (19\%) had other conditions as warfarin indications. The patients' data were recorded during routine clinic follow-up, and the INR values were recorded from the hospital records. The patients' INR data were extracted for the period of January 1, 2014-December 31, 2014. TTR was calculated as the proportion of days with INR values between the target INR (2.0-3.0 or 2.5-3.5). The safety and efficacy of warfarin therapy are dependent on maintaining the INR within the target is 2.5 (range 2.0-3.0) for patients with a mechanical aortic valve, nonvalvular AF, and other reasons. The target of INR value was $3(2.5-3.5)$ in patients with a mechanical mitral valve and/or mechanical heart valves in both the aortic and mitral position. ${ }^{[10]}$ TTR was calculated according to F. R. Roosendaal's algorithm with linear interpolation. ${ }^{[1]}$

For the hypothesis of the present study, we divided patients into two groups; adequate INR control when TTR $\geq 70 \%$ (Group-1, $n=1068,21.4 \%$ ) and inadequate INR control when TTR $<70 \%$ (Group-2, $n=3919,78.6 \%$ ). All demographic and clinic characteristics of the patients were compared to determine possible factors that might be cause adequate warfarin use.

\section{Statistical analysis}

The continuous variables were presented as mean \pm standard deviation, and the categorical variables were expressed as number and percentage (\%). The continuous variables were compared with the Student's $t$-test or the Mann-Whitney U-test. Chi-square test or Fisher's exact test were used to compare categorical variables. The homogeneity of the variances was tested with Levene's test. To determine the independent predictors of TTR $\geq 70 \%$, the logistic regression analysis was structured. The possible factors that identified with univariate analyses were entered into the logistic regression analysis. The Statistical Package for the Social Sciences (SPSS for Windows, Version 20.0, SPSS Inc., Chicago, IL, USA) was used for the statistical analysis. $P<0.05$ was determined as statistically significant.

\section{RESULTS}

Of the 4987 patients included in the Warfarin-TR study, only one in fifth had adequate anticoagulation control (Group 1, $n=1068,21.4 \%)$. Baseline demographic and clinical characteristics of the two groups are summarized in Table 1.

\begin{tabular}{|c|c|c|c|}
\hline \multicolumn{4}{|c|}{$\begin{array}{l}\text { Table 1: Baseline clinical and demographic } \\
\text { characteristics of groups }\end{array}$} \\
\hline Variables & $\begin{array}{c}\text { Group 1 } \\
(n=1068) \\
n(\%)\end{array}$ & $\begin{array}{c}\text { Group } 2 \\
(n=3919) \\
n(\%)\end{array}$ & $P$ \\
\hline Age (year) and mean \pm SD & $60.6 \pm 13.5$ & $60.8 \pm 13.3$ & 0.638 \\
\hline Female & $582(54.5)$ & $2167(55.3)$ & 0.641 \\
\hline $\mathrm{TTR}(\%)$ and mean $\pm \mathrm{SD}$ & $80 \pm 8.5$ & $40.9 \pm 17.2$ & $<0.001$ \\
\hline $\begin{array}{l}\text { Number of INR monitoring } \\
1 \text { year and mean } \pm \text { SD }\end{array}$ & $10.3 \pm 3.5$ & $10.2 \pm 2.8$ & 0.294 \\
\hline Hypertension & $549(51.4)$ & $2209(56.4)$ & 0.004 \\
\hline Diabetes mellitus & $229(21.4)$ & $811(20.7)$ & 0.594 \\
\hline Current smoker & $214(20.0)$ & $821(20.9)$ & 0.515 \\
\hline Hyperlipidemia & $237(22.2)$ & $832(21.2)$ & 0.497 \\
\hline Atrial fibrillation & $641(60.0)$ & $2231(56.9)$ & 0.070 \\
\hline Heart failure & $242(22.7)$ & $979(25.0)$ & 0.118 \\
\hline Antiplatelet agent use & $243(22.8)$ & $962(24.5)$ & 0.225 \\
\hline Coronary artery disease & $240(22.5)$ & $916(23.4)$ & 0.536 \\
\hline Pulmonary embolism & $53(5.0)$ & $196(5.0)$ & 0.959 \\
\hline Deep venous thrombosis & $43(4.0)$ & $231(5.9)$ & 0.018 \\
\hline Cerebrovascular event & $101(9.5)$ & $364(9.3)$ & 0.866 \\
\hline Chronic kidney disease & $89(8.3)$ & $215(5.5)$ & 0.001 \\
\hline $\begin{array}{l}\text { Following doctor } \\
\text { (cardiologist) }\end{array}$ & $1018(95.3)$ & $3611(92.3)$ & $<0.001$ \\
\hline Any bleeding event & $198(18.4)$ & $807(20.6)$ & 0.138 \\
\hline Major bleeding & $33(3.1)$ & $12(3.2)$ & 0.869 \\
\hline Minor bleeding & $165(15.4)$ & $682(17.4)$ & 0.132 \\
\hline \multicolumn{4}{|l|}{ Warfarin use reason } \\
\hline NVAF & $433(40.5)$ & 1485 (37.9) & 0.078 \\
\hline MHV & $456(42.7)$ & $1666(42.5)$ & \\
\hline Other & $179(16.8)$ & $768(19.8)$ & \\
\hline
\end{tabular}

MHV: Mechanical heart valve, NVAF: Nonvalvular atrial

fibrillation, SD: Standard deviation, TTR: Time in therapeutic range,

INR: International normalized ratio

The mean age of the study population was $60.7 \pm 13.5$ years, and there was no significant difference between the two groups. The mean TTR value of Group 1 was significantly higher than Group $2(80 \pm 8.5$ vs. $40.9 \pm 17.2 ; P<0.001)$. The traditional cardiovascular risk factors were similar between groups except hypertension (Group 1 51.4\%, Group 2 56.4\%; $P=0.004$ ) and chronic kidney disease (Group $18.3 \%$, Group 2 5.5\%; $P=0.001)$. There were no statistically significant differences between groups regarding warfarin use reason. Although majority of the patients were followed by a cardiologist, the number of patients who followed by a cardiologist were significantly higher in Group 1 than Group 2 (95.3\% vs. 92.3\%; $P<0.001)$. Even though any bleeding and minor bleeding events were higher in Group 2 than Group 1, it was not statistically significant. Furthermore, the major bleeding rate was similar between groups [Table 2]. The awareness of warfarin use which determined with three questions, known to use warfarin, known to the reason of warfarin use, and known to food-drug interactions with warfarin, was significantly higher in Group 1 than Group 2 [Figure 1]. Multivariate logistic regression analysis revealed that age (odds ratio [OR], $1.007 ; 95 \%$ confidence interval $[\mathrm{CI}], 1.002-1.013 ; P=0.014)$, 
hypertension (OR, 0.821; 95\% CI, 0.707-0.955; $P=0.01$ ), AF (OR, 1.180; 95\% CI, 1.014-1.374; $P=0.033$ ), chronic kidney disease (OR, 1.697; 95\% CI, 1.301-2.215; $P<0.001$ ), to known warfarin use reason (OR, 1.699; 95\% CI, 1.341-2.153; $P<0.001)$, and known to food-drug interaction with warfarin (OR, 1.583; 95\% CI, 1.350-1857; $P<0.001$ ) were independent predictors of adequate coagulation [Table 3].

\section{DISCUSSION}

Our study that reflecting daily practice determined that only one-fifth of the patients who use warfarin for any reason have adequate coagulation. In addition, the mean TTR value of groups was dramatically different. This result showed that the patients with adequate coagulation control had highly good control; however, the patients with inadequate coagulation have extremely poor control. Moreover, our results revealed that the awareness of warfarin use of patients with adequate coagulation was significantly higher than inadequate coagulation, and it is independent predictors of adequate coagulation.

\begin{tabular}{lccc}
\hline \multicolumn{4}{l}{ Table 2: Comparison of bleeding ratio between groups } \\
\hline Bleeding type & $\begin{array}{c}\text { Group 1 } \\
(\boldsymbol{n}=\mathbf{1 0 6 8 )}, \boldsymbol{n}(\%)\end{array}$ & $\begin{array}{c}\text { Group 2 } \\
(\boldsymbol{n}=\mathbf{3 9 1 9 )}, \boldsymbol{n}(\%)\end{array}$ & $\boldsymbol{P}$ \\
\hline Any bleeding & $198(18.4)$ & $807(20.6)$ & 0.138 \\
event & & & \\
Major bleeding & $33(3.1)$ & $12(3.2)$ & 0.869 \\
Minor bleeding & $165(15.4)$ & $682(17.4)$ & 0.132 \\
\hline
\end{tabular}

\begin{tabular}{|c|c|c|c|}
\hline Variable & OR & $95 \% \mathrm{CI}$ & $P$ \\
\hline Age & 1.007 & $1.002-1.013$ & 0.014 \\
\hline Hypertension & 0.821 & $0.707-0.955$ & 0.010 \\
\hline Atrial fibrillation & 1.180 & $1.014-1.374$ & 0.033 \\
\hline Chronic kidney disease & 1.697 & $1.301-2.215$ & $<0.001$ \\
\hline To know warfarin use reason & 1.699 & $1.341-2.153$ & $<0.001$ \\
\hline Know to food-drug interaction with & 1.583 & $1.350-1857$ & $<0.001$ \\
\hline
\end{tabular}
warfarin

CI: Confidence interval, OR: Odds ratio

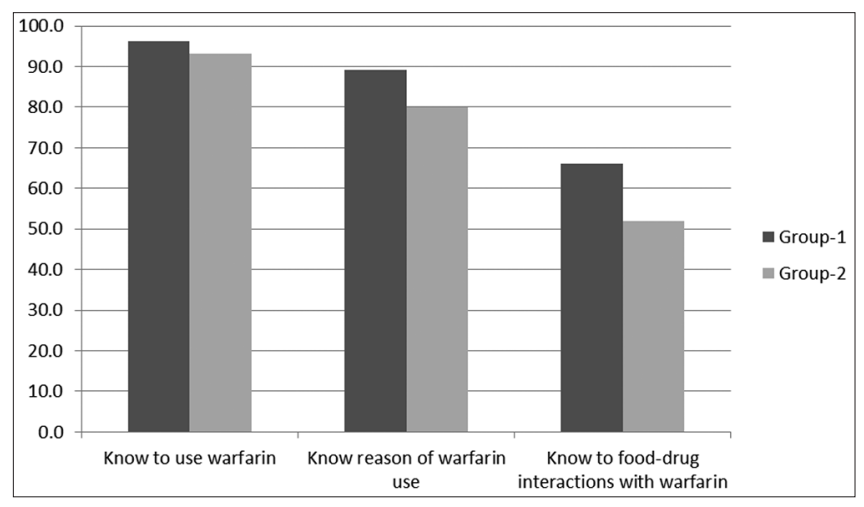

Figure 1: Comparison of awareness of warfarin use
Our results are fairly consistent with previous studies that conducted in Turkish patients. ${ }^{[12-14]}$ In their study, Turk et al. reported that the mean TTR was $42.3 \% \pm 18.4 \%$ in patients with valvular and nonvalvular AF. In the same study, 44\% of patients had TTR $<40 \% .{ }^{[12]}$ Ertaş et al. conducted a study that included 2242 patients with at least one AF episode reported that only $41.3 \%$ of all patients had adequate INR levels. ${ }^{[13]}$ Furthermore, the study conducted by our group have shown that although mean TTR level was favorable in warfarin specialized outpatients clinic $(68.8 \% \pm 15.88)$, it was unfavorable in general cardiology outpatients clinic (51.6\% \pm 23.04$).{ }^{[14]}$ Even though the mean TTR of general cardiology outpatient's clinic is higher than other studies that conducted by Turk and Ertas, it is so far from adequate value. Furthermore, this study has shown the importance of follow-up clinic. In WARFARIN-TR study, we did not evaluate the effect of specialized and general outpatient's clinic separately. However, we recorded the physician that follow-up patients. Although the majority of patients followed up by a cardiologist, the number in Group 1 was significantly higher than Group 2. Previous studies have shown that comorbidities such as diabetes mellitus, hypertension, and heart failure might be associated with inadequate TTR control. ${ }^{[15,16]}$ On the contrary of previous studies, in this study, there were no significant differences between groups regarding traditional cardiovascular risk factors except hypertension and chronic kidney disease. Chronic kidney disease is an independent predictor of adequate coagulation. This might be explained by the patients with chronic kidney disease tightly follow-up by their physicians both for kidney function and warfarin use. On the other hand, hypertension is significantly higher in Group 2 that may explain by an explanatory mechanism is the possible interaction between warfarin and drugs administered to hypertension. The awareness of warfarin use is important in achieving the optimal TTR. As we emphasized, above the follow-up, clinics are play an important role in adequate coagulation. ${ }^{[14,17,18]}$ Previous studies have shown that significantly higher TTR level is reached with INR specialized outpatient clinics rather than general clinics follow-up coagulation. ${ }^{[14,17,18]}$ An advantage of INR specialized outpatient clinics is frequent reminding of food-drug interaction with warfarin that might result in better TTR value. In the present study, we showed that the awareness of warfarin use was an independent predictor of adequate coagulation. The safety and efficacy of warfarin therapy depend critically on maintaining the INR within the therapeutic range. ${ }^{[19-22]}$ Many studies found that a vast number of bleeding events occurred when the INR was outside the therapeutic range. ${ }^{[22,23]}$ Similarly, to the previous studies, in this study, the number of any bleeding and minor bleeding were higher in Group 2 than Group 1; however, it was not statistically significant. In contrast to the previous studies, the major bleeding rate was similar between groups. The low number of bleeding might be due to short follow-up periods of patients and also incomplete declarations of patients. 


\section{ConcLusion}

Our study demonstrated that a low proportion of patients taking warfarin achieve an adequate coagulation in daily practice. Furthermore, patients with adequate coagulation were more aware of warfarin use.

\section{Limitations}

The main limitation of our study was that we did not evaluate the stroke rate of the patient during the study period. Another limitation is that due to the study conducted in outpatient clinics, it might be caused by limited answers of patients in some busy outpatients clinics.

\section{Financial support and sponsorship}

Nil.

\section{Conflicts of interest}

There are no conflicts of interest.

\section{RefERENCES}

1. Hylek EM, Go AS, Chang Y, Jensvold NG, Henault LE, Selby JV, et al. Effect of intensity of oral anticoagulation on stroke severity and mortality in atrial fibrillation. N Engl J Med 2003;349:1019-26.

2. Hart RG, Pearce LA, Aguilar MI. Meta-analysis: Antithrombotic therapy to prevent stroke in patients who have nonvalvular atrial fibrillation. Ann Intern Med 2007;146:857-67.

3. White HD, Gruber M, Feyzi J, Kaatz S, Tse HF, Husted S, et al. Comparison of outcomes among patients randomized to warfarin therapy according to anticoagulant control: Results from SPORTIF III and V. Arch Intern Med 2007;167:239-45.

4. Camm AJ, Lip GY, De Caterina R, Savelieva I, Atar D, Hohnloser SH, et al. 2012 focused update of the ESC guidelines for the management of atrial fibrillation: An update of the 2010 ESC guidelines for the management of atrial fibrillation. Developed with the special contribution of the European Heart Rhythm Association. Eur Heart J 2012;33:2719-47.

5. Gallagher AM, Setakis E, Plumb JM, Clemens A, van Staa TP. Risks of stroke and mortality associated with suboptimal anticoagulation in atrial fibrillation patients. Thromb Haemost 2011;106:968-77.

6. Cove CL, Hylek EM. An updated review of target-specific oral anticoagulants used in stroke prevention in atrial fibrillation, venous thromboembolic disease, and acute coronary syndromes. J Am Heart Assoc 2013;2:e000136.

7. Çelik A, İzci S, Kobat MA, Ateş AH, Çakmak A, Çakı1lı Y, et al. The awareness, efficacy, safety, and time in therapeutic range of warfarin in the Turkish population: WARFARIN-TR. Anatol J Cardiol 2016;16:595-600.

8. Kılıç S, Çelik A, Çekirdekçi E, Altay S, Elçik D, Akboğa MK, et al. The prevalence and risks of inappropriate combination of aspirin and warfarin in clinical practice: Results from WARFARIN-TR study. Balkan Med J 2018. [Epub ahead of print].

9. Kılıç S, Çelik A, Çakmak HA, Afşin A, Tekkeşin Aİ, Açıksarı G, et al. The time in therapeutic range and bleeding complications of warfarin in different geographic regions of Turkey: A subgroup analysis of WARFARIN-TR study. Balkan Med J 2017;34:349-55.

10. Guyatt GH, Akl EA, Crowther M, Gutterman DD, Schuünemann HJ; American College of Chest Physicians Antithrombotic Therapy and Prevention of Thrombosis Panel. Executive summary: Antithrombotic therapy and prevention of thrombosis, $9^{\text {th }}$ ed: American College of Chest Physicians Evidence-Based Clinical Practice Guidelines. Chest 2012;141:7S-47S.

11. Rosendaal FR, Cannegieter SC, van der Meer FJ, Briët E. A method to determine the optimal intensity of oral anticoagulant therapy. Thromb Haemost 1993;69:236-9.

12. Turk UO, Tuncer E, Alioglu E, Yuksel K, Pekel N, Ozpelit E, et al. Evaluation of the impact of warfarin time in therapeutic range on outcomes of patients with atrial fibrillation in Turkey: Perspectives from the observational, prospective WATER registry. Cardiol J 2015;22:567-75

13. Ertaş F, Kaya H, Kaya Z, Bulur S, Köse N, Gül M, et al. Epidemiology of atrial fibrillation in Turkey: Preliminary results of the multicenter AFTER study. Turk Kardiyol Dern Ars 2013;41:99-104.

14. Kılıç S, Soner Kemal H, Yüce Eİ, Şimşek E, Yağmur B, Memişoğlu Akgül N, et al. Comparison of warfarin use in terms of efficacy and safety in two different polyclinics. Anatol J Cardiol 2017;18:328-33.

15. Melamed OC, Horowitz G, Elhayany A, Vinker S. Quality of anticoagulation control among patients with atrial fibrillation. Am J Manag Care 2011;17:232-7.

16. Ciurus T, Cichocka-Radwan A, Lelonek M. Factors affecting the quality of anticoagulation with warfarin: Experience of one cardiac centre. Kardiochir Torakochirurgia Pol 2015;12:334-40.

17. Fitzmaurice DA, Hobbs FD, Murray ET, Holder RL, Allan TF, Rose PE. Oral anticoagulation management in primary care with the use of computerized decision support and near-patient testing: A randomized, controlled trial. Arch Intern Med 2000;160:2343-8.

18. Wilson SJ, Wells PS, Kovacs MJ, Lewis GM, Martin J, Burton E, et al. Comparing the quality of oral anticoagulant management by anticoagulation clinics and by family physicians: A randomized controlled trial. CMAJ 2003;169:293-8.

19. Cannegieter SC, Rosendaal FR, Wintzen AR, van der Meer FJ, Vandenbroucke JP, Briët E, et al. Optimal oral anticoagulant therapy in patients with mechanical heart valves. N Engl J Med 1995;333:11-7.

20. Hylek EM, Singer DE. Risk factors for intracranial hemorrhage in outpatients taking warfarin. Ann Intern Med 1994;120:897-902.

21. A randomized trial of anticoagulants versus aspirin after cerebral ischemia of presumed arterial origin. The Stroke Prevention in Reversible Ischemia Trial (SPIRIT) study group. Ann Neurol 1997;42:857-65.

22. Adjusted-dose warfarin versus low-intensity, fixed-dose warfarin plus aspirin for high-risk patients with atrial fibrillation: Stroke prevention in atrial fibrillation III randomised clinical trial. Lancet 1996;348:633-8.

23. Hylek EM, Skates SJ, Sheehan MA, Singer DE. An analysis of the lowest effective intensity of prophylactic anticoagulation for patients with nonrheumatic atrial fibrillation. N Engl J Med 1996;335:540-6. 